\section{ENGEVISTA}

Página da revista: http://www.uff.br/engevista/seer/

\title{
Adsorção como um processo complementar à Hidrodessulfurização na redução da emissão de SOx pela queima de óleo diesel
}

\author{
Caroline Carriel Schmitt ${ }^{1}$ \\ Elaine Vosniak Takeshita ${ }^{2}$ \\ Sandra Shirley Ximeno Chiaro ${ }^{3}$ \\ Carlos Itsuo Yamamoto ${ }^{4}$
}

Resumo: A remoção de compostos de enxofre do diesel através da adsorção em carvão ativado foi investigada, bem como a possibilidade de regeneração aplicando-se a técnica de lavagem por solvente. A adsorção realizada em batelada com diesel sintético e comercial mostrou que é possível remover grande parte do enxofre presente, reduzindo $73 \%$ da concentração de enxofre do diesel sintético e $44 \%$ do diesel comercial. Em leito fixo foi possível atingir $77 \%$ de remoção de enxofre. Além disso, 54,8\% da capacidade adsortiva foi restaurada após a lavagem do carvão ativado empregando-se etanol, mostrando que a adsorção de compostos sulfurados como etapa complementar à Hidrodessulfurização é uma técnica promissora a qual merece destaque na obtenção de níveis reduzidos de sulfurados no diesel comercial.

Palavras-chave: Adsorção, hidrodessulfurização, emissão de $\mathrm{SO}_{\mathrm{x}}$.

\begin{abstract}
The removal of sulphur compounds from diesel fuel through activated carbon adsorption was investigated, as well as the possibility of regeneration by the solvent washing technique. The batch adsorption showed a reduction of $73 \%$ of the sulphur concentration in synthetic diesel as well as $44 \%$ of the sulphur content in commercial diesel fuel. Furthermore, the experiments performed in a fixed bed column showed that it was possible to reach $77 \%$ of sulphur removal. In addition, $54.8 \%$ of the adsorptive capacity was restored
\end{abstract}

\footnotetext{
${ }^{1}$ UFPR - Universidade Federal do Paraná

${ }^{2}$ UFPR - Universidade Federal do Paraná

${ }^{3}$ CENPES - PETROBRAS

${ }^{4}$ UFPR - Universidade Federal do Paraná
} 
ISSN: $1415-7314$

ISSN online: $2317-6717$

after regeneration using ethanol. These results indicate that the adsorption of sulphur compounds as a complementary treatment to Hydrodesulphurization is a promising technique that deserves attention aiming reduced levels of pollutants in diesel fuel

Keywords: Adsorption, hydrodesulphurization, $\mathrm{SO}_{\mathrm{x}}$ emission

\section{Introdução}

Seguindo as tendências internacionais, o governo brasileiro vem sendo mais restritivo quanto à emissão de poluentes gerados pela queima de combustíveis fósseis no Brasil. Uma das principais medidas adotadas é a redução de enxofre dos combustíveis, uma vez que os óxidos de enxofre gerados durante a combustão são responsáveis pela formação de chuva ácida, problemas relacionados à corrosão, além de outros problemas ambientais (Navarro, 2007; Petrobras, 2011; Santos, 2005).

Dentre os derivados do petróleo, o óleo diesel corresponde a 51\% do consumo doméstico de combustíveis fósseis em território nacional, conforme dados do Ministério de Minas e Energia (2011). Tendo em vista sua alta demanda e a necessidade de medidas mais restritivas quanto à emissão de poluentes nocivos, foi lançado o Programa de Controle de Poluição do Ar por Veículos Automotores (PROCONVE), no qual dentre outras medidas, o teor de enxofre presente no óleo diesel foi sendo reduzido gradualmente de concentrações na faixa de 500 ppm para $10 \mathrm{ppm}$ em 2013 (Proconve, 2012).

Atualmente o processo bem estabelecido de redução de compostos sulfurados adotados pelas refinarias é a Hidrodessulfurização (HDS), o qual converte o enxofre em sulfeto de hidrogênio, através do emprego de catalisadores, alta pressão e temperatura. Com isso, as condições de operação do processo HDS tornam este processo de alto custo (Babich e Moulijn, 2003; Pawelec, et al., 2011).

Os compostos de enxofre presentes no diesel reagem de maneira distinta no processo HDS. Enquanto sulfetos, disulfetos e seus aquilados reagem prontamente, compostos aromáticos como benzotiofeno, dibenzotiofeno e seus alquilados são menos reativos. Isto se deve ao tamanho dos anéis aromáticos e a posição dos grupos aquilados (Bandosz, 2006; Song e Ma, 2003; Stanislaus, et al., 2010; Yang, 2003; Xiao, et al, 2008).

Tendo em vista as condições severas de processo necessárias para a remoção de enxofre pelo processo HDS, a utilização desta tecnologia para este fim apresenta elevado custo quando baixas concentrações de enxofre são requeridas. Alguns estudos demonstraram que para reduzir de 500 ppm para 15 ppm de enxofre, seriam necessários um aumento de três vezes da atividade 
catalítica ou triplicar o volume do reator, o que demanda altos investimentos (Pawelec et al., 2011; Hernández-Maldonado e Yang, 2004; Ma et al., 2002).

Com isso, a busca por processos alternativos ao HDS vem sendo investigada pela comunidade científica nos últimos anos.

Um dos processos que apresenta potencial como processo complementar é a adsorção através do emprego de carvão ativado. Esta tecnologia requer baixa pressão, baixas temperaturas de operação além de baixo consumo energético, além de ser possível restaurar a capacidade adsortiva do adsorvente através de processos simples de recuperação, permitindo a utilização do adsorvente em mais de um processo adsortivo, reduzindo custo e resíduos. Além disso, a adsorção apresenta certas vantagens, tendo em vista a possibilidade de remoção dos compostos sulfurados (benzotiofenos, dibenzotiofenos e seus derivados alquilados) de difícil remoção pelo método convencional adotado pelas refinarias (Bandosz, 2006; Song e Ma, 2003; Stanislaus et al., 2010; Yang, 2003; Xiao et al., 2008).

Quando comparado com outros adsorventes, o carvão ativado apresenta vantagens, tendo em vista sua elevada área superficial e grande volume de poros, sendo capaz de adsorver mais compostos não polares e fracamente polares que outros adsorventes (Yang, 2003).

Normalmente, o processo de adsorção engloba duas etapas principais: a etapa de adsorção e a etapa de regeneração, a qual visa a recuperação da capacidade adsortiva do carvão ativado e, em muitos casos, a recuperação dos compostos adsorvidos (Suzuki, 1989).

Existem diferentes técnicas desenvolvidas para a regeneração dos adsorventes, porém a regeneração pela lavagem com solventes apresenta certas vantagens tratando-se da dessulfurização adsortiva, uma vez que evita a emissão de $\mathrm{SO}_{x}$ gerado pela regeneração oxidativa ou $\mathrm{H}_{2} \mathrm{~S}$ gerado pela regeneração redutiva. Além disso, é um processo que pode ser facilmente implantado num processo de produção, permitindo a recuperação dos solventes (Lin et al., 2011; Guo et al., 2011).

Tendo em vista a possibilidade de aplicação de carvão ativado como um complemento ao processo HDS na redução da concentração de sulfurados do óleo diesel, aliada à possibilidade de recuperar a capacidade do adsorvente pelo processo de regeneração por um solvente não tóxico e de baixo custo, neste trabalho foi investigada a aplicação do carvão ativado na remoção de compostos de enxofre de amostras de óleo diesel sintético e comercial, bem como a capacidade de regeneração utilizando etanol. A capacidade de adsorção dos sulfurados em um sistema dinâmico, empregando leito fixo também foi investigada.

\section{Experimentos}

\subsection{Carvão Ativado}


O carvão ativado de endocarpo de coco da palmeira de Babaçu (Orbignya Phalerata), ativado processo físico (vapor d'água a $900{ }^{\circ} \mathrm{C}$ ), foi fornecido por um fabricante local. As características físico-químicas, conforme dados do fornecedor, estão descritas na Tabela 1 abaixo :

Tabela 1: Características físico-químicas do carvão ativado

\begin{tabular}{ccccc}
\hline $\begin{array}{c}\text { Umidade } \\
(\% \mathbf{w} / \mathbf{w})\end{array}$ & $\begin{array}{c}\text { Índice de Iodo } \\
\left(\mathbf{M g I}_{2} / \mathbf{g}\right)\end{array}$ & $\begin{array}{c}\text { Índice de Melaço } \\
(\%)\end{array}$ & $\begin{array}{c}\text { Massa Específica } \\
(\mathbf{g} / \mathbf{m L})\end{array}$ & $\mathbf{p H}$ \\
\hline 2,2 & 939,0 & 54,0 & 0,45 & 7,0 \\
\hline
\end{tabular}

O número de Iodo fornece um índice de porosidade relativo aos microporos do carvão ativado (0 a $20 \AA$, ou até $235 \mathrm{~nm}$ ) por adsorção de iodo a partir de uma solução. Isso é equivalente a uma área superficial entre $900 \mathrm{~m}^{2} / \mathrm{g}$ e $1100 \mathrm{~m}^{2} / \mathrm{g}$ (Activated Carbon Manufacturer, 2013). Já o índice de melaço é uma medida do teor de mesoporos do carvão ativado (maior do que $20 \AA$, ou maior do que $2 \mathrm{~nm}$ ) indicando uma adsorção elevada de moléculas grandes.

A caracterização textural do carvão ativado foi realizada pelo método de adsorção/dessorção de $\mathrm{N}_{2}$ a $77 \mathrm{~K}$. A análise foi realizada no equipamento Tristar 3000, marca Micromeritics. A área interna superficial dos adsorventes, tamanho, volume e distribuição do tamanho dos poros foram obtidos pelo método B.J.H. Os dados são apresentados na Tabela 2.

Tabela 2: Caracterização textural do carvão ativado

\begin{tabular}{ccccc}
\hline $\begin{array}{c}\text { Área B.E.T } \\
\left(\mathbf{m}^{2} / \mathbf{g}\right)\end{array}$ & $\begin{array}{c}\text { Área } \\
\text { Superficial } \\
\text { Externa } \\
\left(\mathbf{m}^{\mathbf{2}} / \mathbf{g}\right)\end{array}$ & $\begin{array}{c}\text { Área de } \\
\text { Microporos } \\
\left(\mathbf{m}^{2} / \mathbf{g}\right)\end{array}$ & $\begin{array}{c}\text { Volume de } \\
\text { Microporos } \\
\left(\mathbf{c m}^{\mathbf{3}} / \mathbf{g}\right)\end{array}$ & $\begin{array}{c}\text { Diâmetro Médio } \\
\text { dos Poros } \\
(\AA)\end{array}$ \\
\hline 758 & 127 & 631 & 0,294 & 20,0 \\
\hline
\end{tabular}

\subsection{Reagentes}

Duas amostras de diesel foram utilizadas no desenvolvimento do trabalho, na qual a amostra denominada diesel sintético foi preparada em laboratório e a outra, denominada diesel comercial, foi fornecida pela refinaria Getúlio Vargas - REPAR, localizada em Araucária, Paraná. A amostra sintética era composta por uma matriz de n-decano, $251 \mathrm{ppm}$ de benzotiofeno (Composto sulfurado). Já o diesel comercial adotado, era livre de aditivos e de biodiesel, e sua caracterização, realizada pelo Laboratório de Análises de Combustíveis Automotivos (LACAUTets), localizado na Universidade Federal do Paraná, está descrita na Tabela 3.

Tabela 3: Propriedades físico-químicas do diesel comercial

\begin{tabular}{lcc}
\hline \multicolumn{1}{c}{ Parâmetros } & Resultado & Metodologia \\
\hline Ponto de Fulgor $\left({ }^{\circ} \mathrm{C}\right)$ & 92,0 & ASTM D93 \\
\hline Enxofre Total $(\mathrm{mg} / \mathrm{Kg})$ & 235 & ASTM D5453 e D4294 \\
\hline
\end{tabular}


ISSN: $1415-7314$

ISSN online: 2317-6717

\begin{tabular}{lcc}
\hline Nitrogênio Total $(\mathrm{mg} / \mathrm{Kg})$ & 245 & ASTM D4629 \\
\hline Teor de Biodiesel $(\%)$ & 0,0 & EN 14078 \\
\hline $\begin{array}{l}\text { Massa Específica a } 20{ }^{\circ} \mathrm{C} \\
\left(\mathrm{g} / \mathrm{cm}^{3}\right)\end{array}$ & 0,841 & ASTM D4052 \\
\hline Cor ASTM & L 0,5 & ASTM D1500 \\
\hline Viscosidade a $40{ }^{\circ} \mathrm{C}\left(\mathrm{mm}^{2} / \mathrm{s}\right)$ & 3,3212 & ASTM D445 \\
\hline Viscosidade a $70{ }^{\circ} \mathrm{C}\left(\mathrm{mm}^{2} / \mathrm{s}\right)$ & 1,9359 & ASTM D445 \\
\hline Destilação & & \\
\hline Ponto Inicial de Ebulição & 213 & ASTM D86 \\
$\left({ }^{\circ} \mathrm{C}\right)$ & & \\
\hline $10 \%$ vol. Recuperado $\left({ }^{\circ} \mathrm{C}\right)$ & 241 & \\
\hline $50 \%$ vol. recuperado $\left({ }^{\circ} \mathrm{C}\right)$ & 274 & \\
\hline $85 \%$ vol. recuperado $\left({ }^{\circ} \mathrm{C}\right)$ & 314 & \\
\hline $90 \%$ vol. recuperado $\left({ }^{\circ} \mathrm{C}\right)$ & 323 & \\
\hline $95 \%$ vol. recuperado $\left({ }^{\circ} \mathrm{C}\right)$ & 336 & \\
\hline Ponto Final de Ebulição $\left({ }^{\circ} \mathrm{C}\right)$ & 352 & \\
\hline
\end{tabular}

O etanol utilizado para os ensaios de regeneração assim como os reagentes utilizados para a preparação da amostra de diesel sintético possuíam grau analítico.

\subsection{Concentração de Enxofre}

A determinação da concentração de enxofre foi realizada através do analisador TRACE SN marca Elementar. O método analítico consiste na injeção de $10 \mu \mathrm{L}$ de amostra líquida em um tubo de combustão catalítico. A concentração de enxofre foi determinada pelo detector de fluorescência de ultravioleta, e a concentração de nitrogênio no detector de quimiluminescência, ambos HORIBA modelo APNA-370.

\subsection{Adsorção em Batelada}

A adsorção em batelada foi realizada adicionando $20 \mathrm{~mL}$ de diesel a $2 \mathrm{~g}$ de carvão ativado previamente seco $\left(130^{\circ} \mathrm{C}\right.$ por 12 horas). O sistema foi mantido a $40^{\circ} \mathrm{C}$ e $150 \mathrm{rpm}$ por $24 \mathrm{~h}$. Em seguida, as amostras foram filtradas e a concentração de enxofre foi então determinada. Uma vez que o excesso de diesel foi removido, as amostras foram regeneradas com etanol. Tanto a adsorção quanto a regeneração foram realizadas no agitador MA 410 Marconi. A capacidade adsortiva (q) foi calculada a partir da equação 1:

$$
q=\frac{\left(C_{0}-C\right) \cdot V \cdot \rho_{L}}{m}
$$


Onde $\mathrm{C}_{0}$ é a concentração de enxofre inicial em ppm $(\mathrm{m} / \mathrm{m}), \mathrm{C}$ é a concentração final de enxofre em ppm $(\mathrm{m} / \mathrm{m}), \mathrm{V}$ é o volume de diesel utilizado $(\mathrm{mL}), \rho \mathrm{L}$ é a massa específica do diesel $(\mathrm{g} / \mathrm{mL})$ e $m$ é a massa de adsorvente $(\mathrm{g})$.

\subsection{Adsorção em Leito Fixo com diesel comercial}

A adsorção em leito fixo foi realizada em uma coluna de quartzo com comprimento de 55 $\mathrm{cm}$ e $2 \mathrm{~cm}$ de diâmetro. A coluna foi preenchida com carvão ativado previamente seco $\left(130{ }^{\circ} \mathrm{C}\right.$ for 12h). Diesel foi alimentado em fluxo ascendente com uma vazão de $0.5 \mathrm{~mL} / \mathrm{min}$ até a saturação do leito, quando concentração do diesel na entrada e na saída da coluna é a mesma. A capacidade adsortiva até a saturação do leito foi calculada pela equação 2:

$$
q_{s a t}=\frac{C_{0} \cdot Q \cdot 10^{-3}}{m_{A C}} \int_{0}^{t_{s a t}}\left(1-\frac{C_{s a t}}{C_{0}}\right) d t
$$

Onde $\mathrm{C}_{0}$ é a concentração inicial de adsorbato em $\mathrm{ppm}(\mathrm{m} / \mathrm{m})$, Q é a vazão volumétrica $(\mathrm{mL} / \mathrm{min}), m_{A C}=$ e a massa de adsorvente empregado $(\mathrm{g}), C_{s a t}$ é a concentração de adsorbato na saída da coluna em ppm $(\mathrm{m} / \mathrm{m})$.

\subsection{Regeneração em batelada}

Apos a filtração, o carvão ativado utilizado na adsorção em batelada foi regenerado com 20 $\mathrm{mL}$ de solvente. A regeneração foi realizada com agitação de $150 \mathrm{rpm}$ durante 30 minutos. Em seguida o adsorvente foi seco a $130{ }^{\circ} \mathrm{C}$ for $12 \mathrm{~h}$ e uma nova etapa de adsorção foi realizada. A capacidade de recuperação da capacidade adsortiva foi determinada pela equação 3 :

$$
\% \operatorname{Re} \text { cuperada }=\frac{q_{(m g / g-A C)}}{q_{0(m g / g-A C)}} \cdot 100
$$

Onde $\mathrm{q}_{0}$ é a capacidade adsortiva inicial e q é a capacidade adsortiva do carvão regenerado. Além disso, uma amostra controle, a qual não passou pelo processo de lavagem com solvente foi avaliada, com o intuito de investigar a capacidade de regeneração pelo solvente.

\section{Resultados}

\subsection{Adsorção em batelada com diesel sintético e diesel comercial}

A partir dos resultados obtidos em batelada, foi possível remover $73 \%$ do conteúdo de enxofre da amostra de diesel sintético, resultando em uma capacidade adsortiva de $1,2974 \mathrm{mg} \mathrm{S} / \mathrm{g}$ CA, o que mostra a grande afinidade do carvão ativado pelos compostos sulfurados e sua capacidade de ser aplicado em amostras de diesel comercial. Com isso, a adsorção utilizando a amostra de diesel comercial, removeu $44 \%$ do conteúdo de enxofre do diesel. Tendo em vista a 
maior complexidade do combustível comercial, composta por centenas de compostos químicos, adsorções competitivas podem ocorrer, reduzindo a capacidade de remoção dos compostos sulfurados, quando comparado ao desempenho obtido pela amostra artificial (Wang et al., 2012). Em amostras sintéticas, a adsorção de enxofre não compete com uma ampla gama de compostos como no caso do diesel comercial, na qual a presença de hidrocarbonetos pode vir a interferir, devido às interações dispersivas entre os compostos poliaromáticos e as regiões ricas em grafeno do adsorvente (Bu et al., 2011). Desta forma, a capacidade adsortiva obtida empregando-se o diesel comercial foi de $0,8631 \mathrm{mg} \mathrm{S} / \mathrm{g}$ CA.

A figura 1 apresenta a concentração inicial $\left(\mathrm{C}_{0}\right)$ e final $(C)$ de enxofre em ambas as amostras de diesel comercial e diesel sintético.

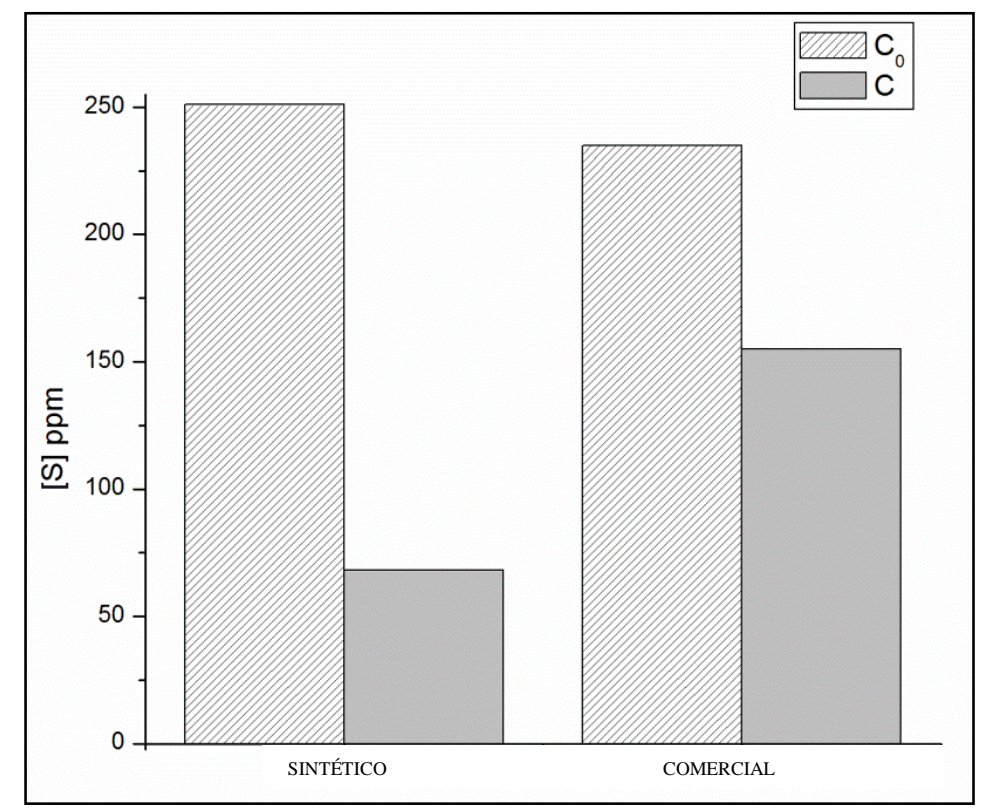

Figura 1: Concentração de enxofre no diesel comercial e diesel sintético antes $\left(\mathrm{C}_{0}\right)$ e após (C) adsorção com carvão ativado

A redução da concentração de enxofre observada em ambas as amostras (sintética e comercial) demonstrada na Figura 1, pode ser atribuída à afinidade dos compostos sulfurados pelos grupos superficiais presentes na superfície do carvão, assim como pela influência da estrutura microporosa. O carvão ativado avaliado apresenta tamanho médio de poros (20 ̊) os quais permitem que as moléculas de compostos sulfurados entrem em contato com a superfície interna do carvão, uma vez que as moléculas dos sulfurados presentes no diesel comercial (BT, DBT e 4,6DMDBT), assim como do composto presenta na amostra sintética (BT), apresentam diâmetro crítico de $6.92 \AA$, 8 A e 9 A, respectivamente (Xiao et al., 2008; Bu et al., 2011).

\subsection{Adsorção em Leito Fixo de Diesel Comercial}


A performance do adsorvente foi também avaliada em um sistema dinâmico. A adsorção em leito fixo de carvão ativado apresentou uma capacidade adsortiva de $1,31 \mathrm{mg} \mathrm{S} / \mathrm{g}$ CA pelos compostos sulfurados do óleo diesel, sendo observada uma redução de aproximadamente $77 \%$ do conteúdo de enxofre, reduzindo a concentração de $235 \mathrm{ppm}(\mathrm{m} / \mathrm{m})$ para $54 \mathrm{ppm}(\mathrm{m} / \mathrm{m})$. A saturação do leito, momento no qual a concentração de enxofre na entrada do leito se iguala à concentração de saída, ocorreu após aproximadamente 1178 minutos (aproximadamente 19 horas), resultando em uma curva alongada, conforme observado na Figura 2. A curva de ruptura alongada e o elevado tempo até a saturação do leito se deve, muito provavelmente à complexa mistura de hidrocarbonetos presente no diesel comercial, com estruturas similares às estruturas dos sulfurados, fenômeno também observado para os compostos nitrogenados (Bu et al., 2011; Wang, et al., 2012).

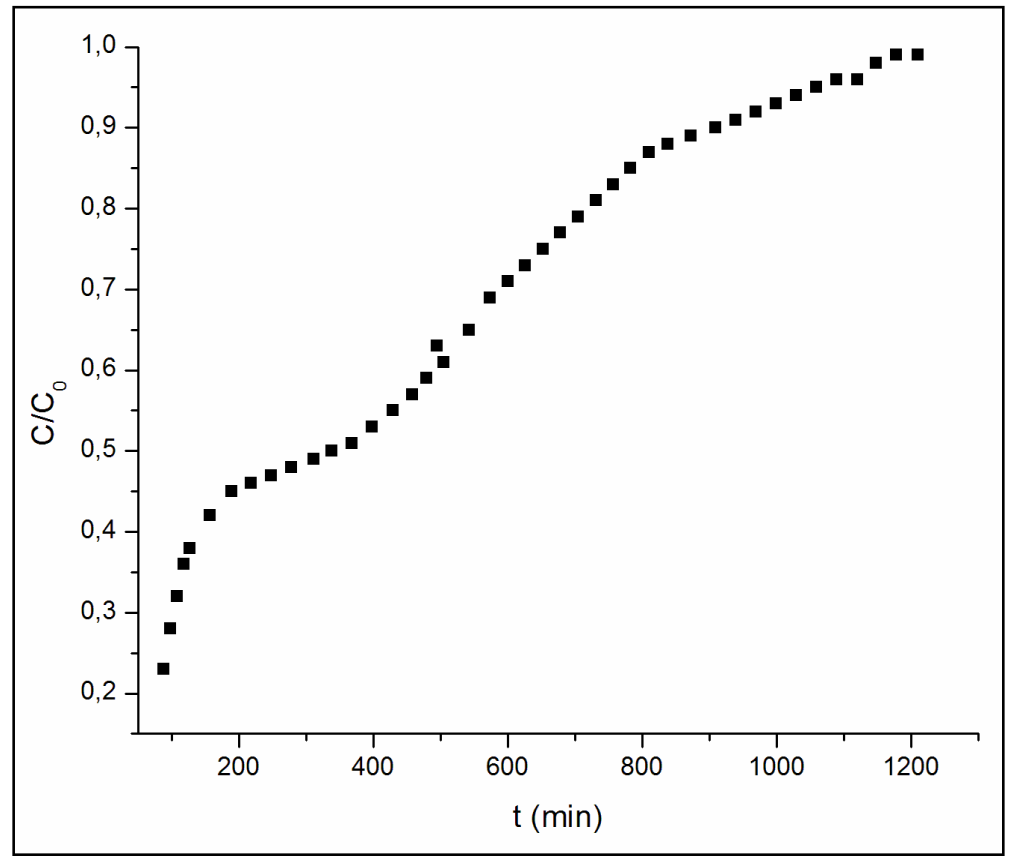

Figura 2: Curva de Ruptura obtida para a remoção de enxofre em Diesel Comercial.

\subsection{Regeneração com etanol}

A capacidade adsortiva do carvão ativado utilizado em batelada com diesel comercial, antes e após a regeneração do adsorvente, assim como uma amostra controle, que passou pelas duas adsorções consecutivas, porém sem a lavagem com solvente, estão demonstrados na Tabela 1:

Tabela 1. Recuperação da capacidade adsortiva do carvão ativado antes e após a regeneração com solvente

\begin{tabular}{ccc}
\hline & q1 (mg S/g AC) & q2 $(\mathbf{m g ~ S / g A C})$ \\
\cline { 1 - 1 } Amostra Controle & 0,8631 & 0,4729 \\
\cline { 1 - 1 } & & 0,3711 \\
\hline
\end{tabular}


A regeneração com etanol recuperou $54,8 \%$ da capacidade adsortiva inicial do adsorvente, mostrando que a lavagem com etanol se mostrou promissora, uma vez que a amostra controle, que não passou por duas adsorções consecutivas apresentou capacidade adsortiva inferior à amostra que passou pelo processo de lavagem. Desta forma, maiores investigações com o intuito de melhor compreender este fenômeno são necessárias. Apesar da lavagem recuperar parte da capacidade adsortiva, a diminuição na capacidade de remoção dos contaminantes pode ser justificada pela redução dos sítios disponíveis para adsorção, os quais vão sendo continuamente ocupados pelos contaminantes, reduzindo a eficiência do adsorvente. Além disso, outros autores observaram que conforme o número de adsorções aumenta para um dado adsorvente, a deposição de substâncias orgânicas nos poros dos adsorventes reduz a capacidade adsortiva consecutiva (Guo et al., 2011).

\section{Conclusão}

O carvão ativado reduziu $73 \%$ do conteúdo de enxofre para uma amostra de diesel sintético e $44 \%$ do conteúdo de enxofre em diesel comercial, em um sistema em batelada, sendo que esta diferença pode ser relacionada à diferença na complexidade das amostras investigadas. Quando avaliado em um sistema dinâmico, foi possível reduzir a concentração de enxofre para 54 ppm, sendo que a saturação do leito ocorreu após aproximadamente 19h de adsorção.

Utilizando etanol como dessorvente, foi possível recuperar 54,8\% da capacidade adsortiva inicial do carvão ativado, cerca de 11,8\% superior à amostra controle, porém maiores investigações são necessárias com o intuito de regenerar o carvão em mais de um ciclo de adsorção.

Desta forma, a aplicação da adsorção como um processo complementar ao HDS se mostrou uma alternativa promissora, tendo em vista a habilidade do carvão ativado em remover os compostos sulfurados, a possibilidade de regeneração, o baixo custo e a simplicidade do processo.

\section{Referências}

ACTIVATED CARBON-MANUFACTURER. The properties of activated carbon. Disponivel em:http://www.activated-carbon-manufacturer.com/pressrelease/company-news/111-theproperties-of-activated-carbon.htm. Acesso em 25/03/2013.

BABICH, I. V.; MOULIJN, J. A., 2003. Science and technology of novel processes for deep desulfurization of oil refinery streams: a review. Fuel, v.82, p.607-631.

BANDOSZ, T.J., 2006. Activated carbon surfaces in environmental remediation: Desulfurization on activated carbons. Elsevier: New York.

BRASIL. Ministério de Minas e Energia, 2011. Balanço Energético Nacional 2011. https://ben.epe.gov.br/downloads/Relatorio_Final_BEN_2011.pdf. Acesso em 25/03/2013.

BU, J.; LOH, G.; GWIE, C. G.; DEWIYANTI, S.; TASRIF, M.; BORGNA, A., 2011. Desulfurization of fuels by selective adsorption on activated carbons: Competitive adsorption of polycyclic aromatic sulfur heterocycles and polycyclic aromatic hydrocarbons. Chemical Engineering Journal. v.166. p.207-217. 
GUO, D.; SHI K,; HE, B.; YUAN, X., 2011. Different solvents for the regeneration of the exhausted activated carbon used in the treatment of coking wastewater. Journal of Hazardous Materials. v.186, p.1788-1793.

HERNÁNDEZ-MALDONADO, YANG, R.T., 2004. Denitrogenation of transportation Fuels by Zeolites at ambient temperature and pressure. Angewandte Chemie, v.116 p.1022-1024.

LIN, L.; ZHANG, Y. ZHANG, H.; LU, F., 2011. Adsorption and solvent desorption behavior of ion-exchanged modified $\mathrm{Y}$ zeolites for sulfur removal and for fuel cell applications. Journal of Colloid Interface Science. v.360, p.753-759.

MA, X.; SUN, L.; SONG, C., 2002. A new approach to deep desulfurization of gasoline, diesel fuel and jet fuel by selective adsorption for ultra-clean fuels and for fuel cell applications. Catalysis Today, v.77, p.107 - 116 .

NAVARRO, M.L.M.N., 2007. Dessulfurização da gasolina por adsorção em zeólitas "Y" trocadas com cobre. 184 f. Programa de Pós-graduação em Engenharia Química. Universidade Federal de Santa Catarina, Santa Catarina.

PAWELEC, B.; NAVARRO, R.M.; CAMPOS-MARTIN, J.M.; FIERRO, J.L.G., 2011. Towards near zero sulfur liquid fuels: A perspective review. Catalysis Science Technology. v.1, p. 23-24.

PETROBRAS - Óleo 2011. http://www.br.com.br/wps/portal/portalconteudo/produtos/automotivos/oleodiesel. 25/03/2013.

PROCONVE, 2012 - Disponível em:

http://www.anfavea.com.br/documentos/CARTILHAproconveSPREAD.pdf. Acesso em: 07/12/2011.

RUTHVEN, D.M., 1984. Principles of Adsorption and Adsorption Processes, New York: Wiley Instercience, John Wiley \& Sons.

SANTOS, F.K.G dos, 2005. Remoção de enxofre na mistura ciclohexeno-propanotiol através de processos de adsorção sobre AlPO e MeAPOs. 105 f. Programa de Pós-Graduação em Engenharia Química. Universidade Federal de Campina Grande, Paraíba.

SONG, C.; MA, X. 2003. New design approches to ultra-clean diesel fuels by deep desulfurization and deep dearomatization. Applied Catalysis B: Environmental. v. 41 p. 207-238.

STANISLAUS, A.; MARAFI, A.; RANA, M., 2010. Recent advances in the science and technology of ultra-low sulfur diesel (ULSD) production. Catalysis Today v. 153 p. 1- 68.

SUZUKI, M., 1989. Adsorption Engineering. v.25, Japan: Kodansha YANG, R.T., 2003. Adsorbents: Fundamentals and Applications. New Jersey: John Wiley \& Sons, Inc.

XIAO, J; ZHONG, L.; BING, L.; QIBIN, X; MOXIN, Y., 2008. Adsorption of Benzothiophene and Dibenzothiophene on Ion-Impregnated Activated Carbons and Ion-Exchanged Y Zeolites.

Energy \& Fuel,v. 22, p. 3858-3863.

WANG, L.; SUN, B.; YANG, F.H.;YANG, R.T., 2012. Effects of aromatics on desulfurization of liquid fuel by $\pi$-complexation and carbon adsorbents. Chemical Engineering Science. v.73, p.208217. 